\title{
Research of the Service and Innovation Ability Improvement of Wuxi Science and Technology Communities
}

\author{
Wang Bin \\ Wuxi Vocational Institute of Commerce, Wuxi, China
}

Keywords: science and technology community; service and innovation ability construction of connotation; market orientation

\begin{abstract}
This paper mainly introduced the methods to improve the service and innovation abilities of science and technology community in Wuxi. By strengthening the construction of its connotation, the guidance of sound policy and regulation for community established by the government, and sufficiently carrying out external science and technology service with market-orient operation model could greatly improve the science and technology innovation ability of the community.
\end{abstract}

\section{Introduction}

Science and technology community is a group scientific research organization spontaneously organized by science and technology workers in accordance with specific purposes and objectives. It is a very important part of civil society organizations. A strong and powerful scientific and technical community is able to contribute the prosperity and development of the national science and technology. There are multiple technology communities in Wuxi now which play a key role in local economic development. Although science and technology communities in Wuxi have strong local service ability, there are many deficiencies and a large room to be improved. Taking the transfer function of the government and serving the local science and technology work as the starting point is an important way to furtherly improves the service innovation ability of the science and technology community.

\section{Strengthening the Connotation Construction of Community}

Community connotation construction is the key to improve the service ability. There are many problems of the science and technology community itself which have been existed for a long time. Reasons should be found out and improved one by one from following aspects.

\subsection{Build a full-time team}

Members from science and technology community are all come from different organizations and carry out external scientific service in their spare time. Due to the limitation of time and energy, the service ability is seriously weakened and the community is a not a profit-seeking organization with limited financial resources couldn't give deserved rewards to its members. The daily management work of the community is also heavy therefore the community needs a professional and stable team of full-time managers to carry out the work. In order to attract more talents to participate in the management of science and technology societies, it is recommended that government departments formulate special policies to promote the professionalization of management positions of science and technology communities. At the same time, special funds are arranged to support the science and technology communities so as to relieve the pressure on funds. Only in this way can the management of the communities feel at ease to carry out their work. At the same time, it is necessary to establish an annual appraisal system to stimulate the enthusiasm of the community staff. According to the relevant survey data, the staff mobility of Wuxi science and technology community is still relatively large. The main reason is the non-full-time orientation, and the payment is not proportional to the income. Some communities also try to recruit full-time staff, but lack of enough welfare due to lack of funds, it is difficult to recruit staff[1]. Therefore, on the one 
hand, the management personnel of the community need to be integrated into the state establishment system; on the other hand, the capital investment should be increased so as to ensure the smooth development of community work.

\subsection{Strengthen the training of community professional proficiency of the staff}

External service ability of the science and technology community of mainly depends on the technical level of the members and management skills of community managers. External service of science and technology community is a high level work which is not easily to be replaced. Therefore, it requires the staff has the high level working ability, and follow the leading technology trend. All mentioned above require community members constantly improve themselves. Government can periodically to organize the training to raise science and technology ability through diversified methods, including the introduction of cutting-edge technology, comprehensive management ability training, and regularly invites experts and scholars from different fields to carry out the teaching. Meanwhile evaluation during the training should be intensified to ensure that the training does not become a mere formality. Through constant training, the level of community staff will be gradually enhanced[2].

\subsection{Strengthen the standard community management}

Community members are the main body of external service. The neglect of the management of community members has been existed for a long time. Many members never participate any community activity since they join the community. Regulate the management of community members, attach great importance to the enrollment examination and approval, classify the members and strengthen the performance review and carry out a special reward to incentive the work enthusiasm of community members. Specific work shall be done in following aspects:

Firstly, work out membership regulations in accordance with actual situation of the community. Focus on the quality of the member and the ability to sever the community[3], as well as the long term enthusiasm of serving the community. Make sure that all community members could carry out science and technology service with strong working intention.

Secondly, according to the personal professional background and working intention, classify the community members into daily management members, business developers and professional technical members to explore their potential abilites.

Finally, formulate the regulations to evaluate the performance of the members. Evaluate the working performance on a regular base. Members with outstanding performance shall be rewarded and also dismiss those who haven't participate the community work for a long time.

\section{Establishing and Perfecting Community Policies and Regulations}

Throughout the regions and countries with good development of science and technology communities, there is a complete set of laws and regulations, which determine the legal status of science and technology communities and offer policy protection and regulations.

\subsection{Formulate related laws and regulations}

Community development needs the top-level design and support from the government. Special laws and regulations related to science and technology community should be formulated, and promote the standardized management of science and technology community. It is good to the development of science and technology community. When undertaking transferring functions of the government, there is no explicit laws and regulations to identify the access of some business could be allowed or not, and the science and technology community cannot make the decision, which to some extent, limits the service business scope of science and technology community. Activities carried out by the communities are more academic exchanges and scientific and technological literacy population. Therefore, relevant laws and regulations should be implemented to guide the community how to carry out the service work, also may carry on the standardized management business to science and technology communities. 


\subsection{Establish a financial guarantee and payment system for the transfer of government functions}

The science and technology community is a non-profit voluntary organization, which has its own advantages. For example, the members of the communities have a high professional quality; receive a high recognition from the public with a non-profit nature. Nowadays, the society emphasizes multi-party co-governance which needs the science and technology communities to actively participate in the social development and construction. Since the 18th national congress of the communist party of China (CPC), the government has always emphasized streamlining administration and delegating power. A lot functions needs to be performed by some agents urgently. The science and technology community has the ability to develop third-party services, and the government also urgently needs to improve public services by purchasing services.

There are also many problems in the process, such as the difficulty of timely delivery of government funds to pay for public services.

Especially in the early stage of these project that haven't been set up yet, but still need to do some preparation which needs a lot investment from science and technology community. If the project is cancelled or took over by other companies, the community shall not get paid then. Therefore, it is urgent to establish and improve special incubation fund for science and technology communities[4]

\subsection{Formulate the policies and systems to support the development of science and technology community}

The development of science and technology community cannot be separated from the policy support of the government. First of all, according to their qualifications, they should be classified into unit relying and industry support. Unit replying communities have certain dependence on the units that replying on with weak willingness to actively expand the market and serve the society. With a strong financial dependence, this type of science and technology community should actively explore an improved method and separate the administrative authority from the linked units. Funds shall be supported at early stage, and gradually being decreased until final financial independence.

Industrial support communities have stronger ability of self innovation and development. Focus more on idea guidance during management, walk in the front of industrial technology, lead the industry development, and make more contribution to the development of industry.

\subsection{Improve the management and supervision of the community}

The government should focus on the process supervision rather than the approval of access. Community development should be in different ways. Do not limit the access of communities. As long as conform to the laws and regulations, strict limits on personnel equipment and registered capital and etc are unnecessary.

At present, the government departments are more likely to adopt the means of annual inspection in the management of science and technology communities. As far as it is concerned, many annual inspections are only in the form of passing the exam, and fail to play a good role of supervision and promotion.

How to seek balance in decentralization and supervision is a problem to be considered about. The science and technology community has undertaken a lot of functions of the government, and the government buys technology service from the community. The bilateral cooperation deserves the supervision from the government. In the early stage of the project, government can verify the qualifications of science and technology community. In the process, government may find out problems and request rectifications at any time, and afterward make a good summary of the project.

The supervision of science and technology communities should not only rely on government and self-supervision, but also introduce social forces. In the process of undertaking transfer function of the government, there existing a lot of interests which might easily bring about corruption. Science and technology communities could operate in the sun only introducing the supervision from the third party. Science and technology communities could bring in third party supervision through 
various channels, such as Wechat subscription, website to public the community affairs and guide the third-party to focus and supervise especially in the operation of major projects, the community should actively take the initiative to invite the third party's supervision. In the process of the supervision, people shall be informed of some issues of science and technology community, also it will be a good chance to attract talents to join. [5]

\section{Operate the Community with Market Principles}

The connotation construction of science and technology community has an important role to improve the service innovation ability. However it is not enough just relying on connotation construction, sufficient market competition is conducive to improve the service and innovation ability of the community rapidly.

\subsection{Set up market-oriented management}

Run the community with full usage of market competition concept. Many communities are lack of the sense of competition because they are reply on the research institutes of science and technology with full funding support, which is not good for the development of the community. Only with full market operation and sufficient competition, can the community rapidly improve the ability of external science and technology service. Only by setting up the marketing management concept can the potential of the community be stimulated. Continuously enhance its vitality, make it grows rapidly and improve its ability of external service.

Soften the access system of science and technology community and build a competitive environment. An industry cannot be confined to one community, that is, multiple communities could be set up in the same industry for the community evolution in the full competition environment. It would be helpful to the development of science and technology community.

\subsection{Build a scientific and technological service platform for seamless connection between supply and demand}

From the investigation and research, we found that although science and technology community have the ability and willingness to offer external service, they cannot find the projects. When the government and enterprises need to purchase a technology service, they are not clear which community can undertake and how to make a seamless connection between the supply and demand. This problem can be solved by building an open and transparent technology service platform. Wuxi science and technology association built a network platform is strongly recommended. All information of the science and technology communities are posted on the website, including professional competence, scope of business, at the same time regular information from demand is posted. Both sides from demand and supply can query related information directly through the platform, thus contributing to cooperation. Regular meeting between the supply and demand parties and direct on-site exchange should be held.

Through strengthening the construction of its connotation, the guidance of the policy and regulations established by the government, fully application of market operation mode of external science and technology service, Science and technology communities greatly improve the service and innovation ability.

\section{References}

[1] Ding Xiangqing. Research of the ways to improve the ability of social service ability of Wuxi Science and Technology Community in Micro times [J]. JiangSu Science and Technology Information, 2015(04):9-10.

[2] Wang Huaming. Simple research about the assessment of science and technology community [J]. Association, 2013(10):41-43

[3] Yuan Jing. Problems and the direction of the development of science and technology 
community at Xining [J].Forum of science association. 2014(8):14-15

[4] Wang Jianhua. Case study of taking government transferring functions by science and technology community [J]. 2013(08):58-61

[5] Zhang Xinyin. Research of the functions of science and technology community in China [D]. Lan Zhou University. 2010:34 